\title{
In vitro Evaluation of Shear Bond Strength of Materials Used in Bonding $3 \times 3$ Lingual Retainer
}

\author{
Evaluación in vitro de la Resistencia al Cizallamiento de los \\ Materiales Utilizados en la Adhesión del Retenedor Lingual $3 \times 3$
}

\begin{abstract}
Matheus Melo Pithon*; Caio de Souza Ferraz ${ }^{* *}$ Gabriel Couto de Oliveira* \& Pedro Henrique Bomfim Magalhaes ${ }^{* *}$
\end{abstract}
$\sqrt{ }$

\begin{abstract}
The aim of the present study was to evaluate which material and technique were the best for bonding $3 \times 3$ lingual retainer. One hundred and five bovine mandibular incisors were used, to which contention bars with a standardized size of $7 \mathrm{~mm}$ were bonded to the lingual surface. Initially all teeth received prophylaxis with pumice stone and water. After this they were randomly divided into seven groups, denominated and characterized as follows: Group (1) bars bonded with Transbond XT in accordance with the manufacturer's instructions; (2) Tooth surface etching with self-etching agent Transbond (SEPT) followed by bonding with Transbond XT; (3) Bonding with Transbond Plus Color Change (TPCC) without adhesive; (4) Bonding with TPCC + SEPT; (5) Bonding with restorative composite Z100 + adhesive Prime Bond, (6) Z100 without adhesive and (7) Z100 + SEPT. Before bonding in Groups 1, 3, 5 and 6 the lingual surface was etched with 37\% phosphoric acid for 20 seconds, followed by washing and drying. After bonding the mechanical tests were performed in a Universal mechanical test machine. The values obtained were submitted to the analysis of variance (ANOVA) and afterwards to the Tukey test $(p<0.05)$. We observed absence of statistical differences among Groups 1, 2, 5 and 7 and among Groups 3, 4, 5 and $6(\mathrm{p}<0.05)$. Group 1 presented the highest bond strength value and Group 6 the lowest. It could be concluded that where bonding of lingual retainer is concerned; the best material to use is Transbond XT irrespective of the etching method, followed by composite Z100 etched with SEPT.
\end{abstract}

KEY WORDS: shear strength, composite resins, orthodontic appliances.

\section{INTRODUCTION}

Undesired orthodontic post-treatment tooth movements have been attributed to a series of factors, including reorganization of the periodontal fiber, alterations in growth and type of treatment performed (Cooke \& Sherriff, 2010).

Recurrence of crowding in the anterior region of the mandible after orthodontic treatment needs to be prevented, and it is necessary to use fixed lingual containment (Lee \& Mills, 2009). In the literature there is an immense variety of devices described (Aasen \& Espeland, 2005; Butler \& Dowling, 2005; Gardner et al., 2003; Niegel, 1974; Norton, 1951) used for this purpose, with fixed devices being those of choice, as their use does do not depend on the patient's cooperation.
Fixed containment devices are constituted of segments of smooth or plaited orthodontic wire, which are molded into the shape of the arch and bonded to the teeth either with or without orthodontic composites.

Composites are the materials of choice for bonding lingual retainers, as they are easy to use, involve an adequate working time, and have adequate resistance to masticatory forces (Baysal \& Uysal, 2010; Butler \& Dowling).

Failures in fixed containments occur in three ways: Debonding at the wire/composite interface, or at the composite/enamel interface, and fracture due to stress ofthe wire, with the latter rarely occurring (Cooke \& Sherriff).

Professor, Southwest Bahia State University UESB, Bahia, Brazil. PhD, Orthodontics, University Federal of Rio de Janeiro (UFRJ), Rio de Janeiro, Brazil.

* Student of dentistry Southwest Bahia State University - UESB, Bahia, Brazil. 
Although fixed containment is an established method in contemporary orthodontics, few studies have been dedicated to evaluating which would be the best method of etching and best material for this purpose. Based on this premise the purpose of the present study was to evaluate the best method and material to use for bonding lingual retainer.

\section{MATERIAL AND METHOD}

One hundred and five bovine mandibular permanent incisors were used, which were extracted and stored in a $10 \%$ formaldehyde solution. After 7 days of fixation they were cleaned and the periodontal tissue adhered to their roots was removed. On conclusion of cleaning they were fixed in $25 \times 20$ reduction bushes (PVC, Tigre Joinvile, Brazil), with selfpolymerizing acrylic resin (Clássico, São Paulo, Brazil) and stored in water under refrigeration.

Initially prophylaxis of all the teeth was performed with pumice stone and water for 15 seconds followed by washing and drying for an equal length of time. After this the teeth were randomly divided into 7 groups $(n=15)$ denominated as follows:

1. $37 \%$ phosphoric acid etching for 15 seconds, application of Transbond (3M Unitek, Monrovia, USA) adhesive and fixation with conventional Transbond XT (3M Unitek, Monrovia, USA) in accordance with the manufacturer's instructions;

2. Tooth surface etching with self-etching agent Transbond Self Etching Primer (SEPT) (3M Unitek, Monrovia, USA) followed by bonding with conventional Transbond XT in accordance with the manufacturer's instructions;

3. Bonding with Transbond Plus Color Change (3M Unitek, Monrovia, USA) without adhesive application;

4. Application of SEPT and bonding with Transbond Plus Color Change;

5. 37\% phosphoric acid etching, application of Prime Bond 2:1 adhesive, and bonding with restorative composite Z100 (3M ESPE, São Paulo, Brazil);

6. $37 \%$ phosphoric acid etching and bonding with resin composite Z100 without adhesive;

7. Application of SEPT and bonding with resin composite Z100.
The containment bars were fixed on the lingual surface of the crown with Transbond XT, Transbond Plus Color Change and resin composite Z100. Both phosphoric acid and adhesive Transbond XT, and SEPT were applied on the lingual surface of enamel with an applicator brush. The composites were polymerized with a light-polymerizing unit for 40 seconds. After bonding the teeth were immersed in artificial saliva and kept at a temperature of $37^{\circ} \mathrm{C}$ for 24 hours, and after this the mechanical tests were performed in a Universal mechanical test machine EMIC DL 5000 at a speed of $0.5 \mathrm{~mm}$.

The shear bond strength test results were submitted to the analysis of variance (ANOVA) and afterwards to the Tukey test in order to compare the control with the other treatments.

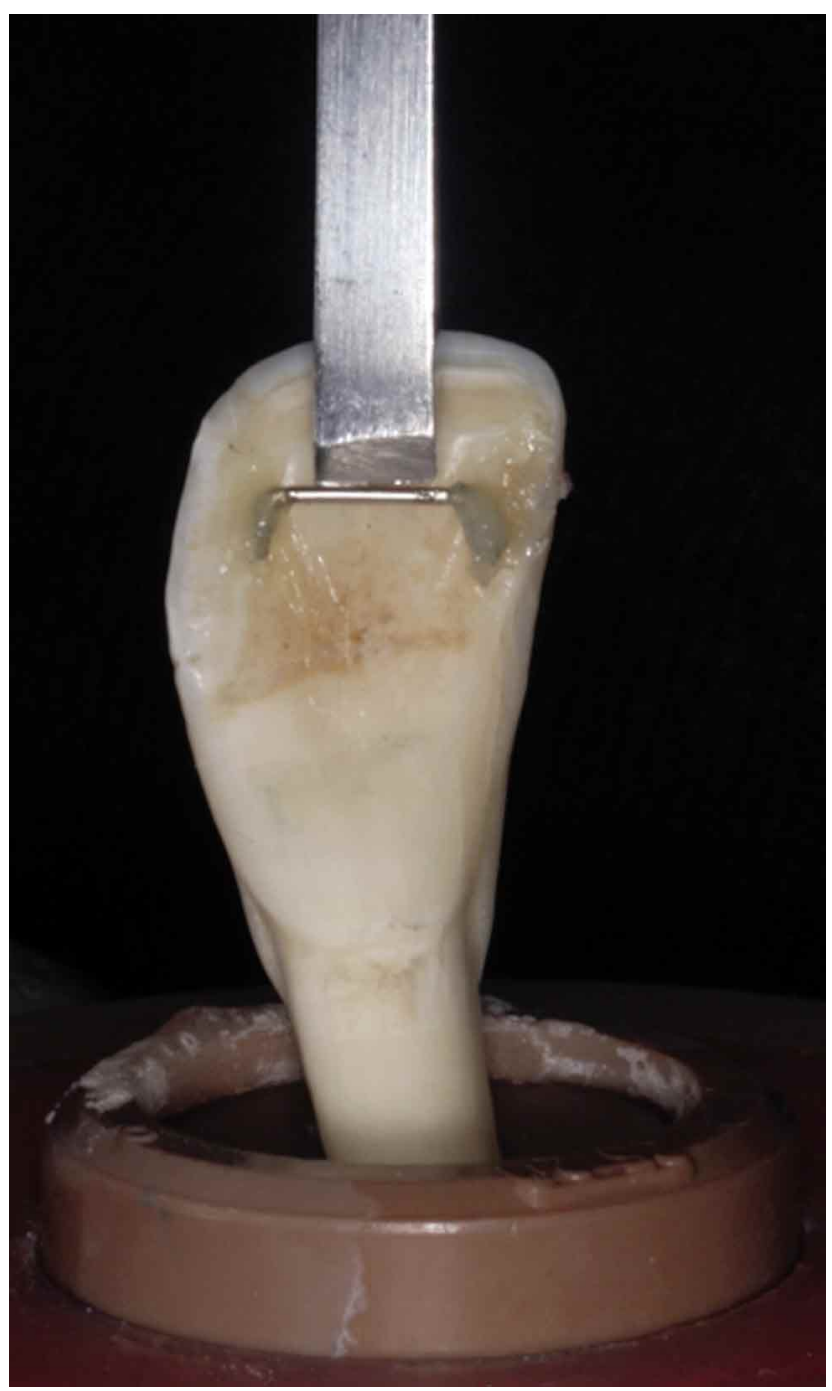

Fig. 1. View of the bond strength test setup. 


\section{RESULTS}

The results demonstrated that the highest bond strength values reached were in Group 1. This group presented statistical differences from Groups 3, 4 and 6 $(p<0.05)$. In turn, Group 1 presented no differences from Groups 2, 5 and 7, thus being the groups that presented the highest means, as demonstrated in Table I.

Table I. Mean, standard deviation of the shear bond strength values, and statistical analysis of the groups evaluated.

\begin{tabular}{llc}
\hline Groups & \multicolumn{1}{c}{ Mean (SD) } & Statistics $^{*}$ \\
\hline 1 & $46.58(11.66)$ & $\mathrm{A}$ \\
2 & $45.88(26.28)$ & $\mathrm{AC}$ \\
3 & $24.12(14.48)$ & $\mathrm{BCD}$ \\
4 & $24.24(18.0)$ & $\mathrm{BCD}$ \\
5 & $29.94(20.88)$ & $\mathrm{ABD}$ \\
6 & $13.6(9.53)$ & $\mathrm{D}$ \\
7 & $40.72(31.16)$ & $\mathrm{AB}$ \\
\hline
\end{tabular}

the absence of statistical differences $(p<0.05)$.

\section{DISCUSSION}

The phenomenon of recurrence is well recognized and documented in orthodontic literature (Arnone, 1999; Artun et al., 1997; Butler \& Dowling). After active treatment is complete, the long term conservation of the corrected tooth positions is the condition both the patient and orthodontist desire (Cooke \& Sherriff).

Fixed lingual contentions are the method of choice for the purpose of orthodontic post-treatment containment. Basically these devices consist of wire bonded with light polymerizable resin composite, along the lingual surfaces of the mandibular anterior incisors, parallel to the incisal of the teeth (Lee \& Mills). This containment is important for reducing undesirable tooth movements after orthodontic treatment.

Although its use is well established in orthodontic clinical practice and in contemporary scientific literature, there is no consensus about the best enamel etching and best material to use in this procedure. The purpose of the present study was to evaluate these requirements; that is to say, the best etching method and best material for bonding $3 \times 3$ containment bars.
To do this, bovine mandibular incisors were used. They were chosen because they present structural similarity to human teeth, and are widely used in scientific researches in which one wishes to test the bond strength of dental materials to tooth enamel.

As related by Usümez et al. (2003), in vivo there is wear of the resin composite that rapidly reduces the superjacent composite thickness, leading to early failure of retainer bonding. The present study did not evaluate the wear of composites, and did not determine the effects of shear bond strength in vivo, being restricted to only in vitro evaluation.

Baysal \& Uysal, in his study reported that in order to guarantee a stronger bond between the enamel and composite, it is imperative to use acid etching. By virtue of this finding, the groups evaluated received enamel etching either with $37 \%$ phosphoric acid or a selfetching agent. Ulker et al. (2009) verified that the adhesive used without acid etching resulted in a significant reduction in tensile strength, confirming that which many industries recommend: Phosphoric acid etching for bonding to enamel.

In the present study, acid etching without the use of adhesive was performed in Groups 3 and 6. These groups presented the lowest bond strength values, proving the importance both of the etching agents, as seen by other authors, and the adhesive. Acid etching forms the gaps that increase the mechanical interlocking and penetration of the adhesive, forming tags improving adhesion. The extension and depth of the etching pattern influence the bond strength of an adhesive, thus the consequence of the surface etching pattern in enamel is reduction of micromechanical retention, and could result in lower tensile strength (Ulker et al.).

When comparing the effectiveness of phosphoric acid with self-etching agents, Ulker et al. obtained results showing that none of the self-etching materials were capable of attaining the effect of phosphoric acid. The present partly confirmed the information found by Ulker et al., seeing that only the teeth whose surfaces were bonded with the composite Transbond XT proved his findings with lower bond strength of the bars bonded with the self-etching agent. Whereas the groups bonded with Transbond Plus Color Change presented no differences with regard to the etching agent. In turn, when composite Z100 was used the highest bond strength values were attained when etching was performed with the self-etching agent. This finding is of clinical interest, 
since the use of TPSEP makes the bonding procedure $65 \%$ faster, according to (White, 2001).

In this study, it is important to observe that the groups in which the composite Transbond XT, (1 and 2) was used obtained better bond strength results than Groups 3 and 4 in which Transbond Plus Color Change was used, (Groups 3 and 4). These results corroborate the findings of Santos et al. (2010) when they evaluated Transbond Plus Color Change on surfaces contaminated with water, blood and saliva.

In the results of the study it was possible to observe that composite Z100 is dependent on the technique, since the results of Group 6, in which the technique was changed with the non-use of adhesive, showed that a lower shear bond strength was obtained.
When the comparing the shear bond strength means presented by the seven groups with the values suggested by Reynolds \& von Fraunhofer (1976) as being adequate for the majority of procedures performed in Orthodontics (between 5.9 and $7.8 \mathrm{MPa}$ ), one finds that the values obtained for the groups were compatible with clinical requirements.

\section{CONCLUSIONS}

It could be concluded that where bonding of lingual retainer is concerned; the best material to use is Transbond XT irrespective of the etching method, followed by composite Z100 etched with the selfetching agent.

PITHON, M. M.; FERRAZ, C. S.; DE OLIVEIRA, G. C. \& MAGALHAES, P. H. B. Evaluación in vitro de la resistencia al cizallamiento de los materiales utilizados en la adhesión del retenedor lingual 3x3. Int. J. Odontostomat., 7(3):395-400, 2013.

RESUMEN: El objetivo fue evaluar cuáles materiales y técnicas eran mejores para la adhesión del retenedor lingual 3×3. Se utilizaron 105 incisivos mandibulares bovinos, a los que se adhirieron barras de contención con un tamaño estándar de $7 \mathrm{~mm}$ en la superficie lingual. Inicialmente todos los dientes recibieron profilaxis con piedra pómez y agua. Luego, se dividieron aleatoriamente en siete grupos, denominados y caracterizados como: Grupo (1) con barras unidas con Transbond XT de acuerdo con las instrucciones del fabricante , (2) Con la superficie del diente grabada con el agente de auto- grabado Transbond (SEPT), seguido por la adhesión con Transbond XT, (3) Adhesión con Transbond Plus Color Change (TPCC ) sin adhesivo, (4) Adhesión con TPCC + SEPT, (5) Adhesión con la resina restauradora Z100 + adhesivo Prime Bond, (6) Adhesión con Z100 sin adhesivo y (7) Z100 + SEPT. Previo a la adhesión en los Grupos 1, 3, 5 y 6 la superficie lingual fue grabada con ácido fosfórico al $37 \%$ durante 20 segundos, lavado y secado. Se realizaron los ensayos con una máquina de ensayo mecánico universal. Los valores obtenidos fueron sometidos al análisis de varianza (ANOVA) y a la prueba de Tukey $(p<0,05)$. No hubo diferencias estadísticas entre los grupos 1, 2, 5 y 7 y entre los Grupos 3, 4, 5 y 6 ( $p<0,05$ ). El grupo 1 presentó el mayor valor de resistencia de adhesión y el Grupo 6 el menor. Se podría concluir que cuando se trata de la adhesión de un retenedor lingual, el mejor material para usar es Transbond XT independiente del método de grabado, seguido de la resina Z100 grabada con SEPT.

PALABRAS CLAVE: resistencia al corte, resinas compuestas, aparatos de ortodoncia.

\section{REFERENCES}

Aasen, T. O. \& Espeland, L. An approach to maintain orthodontic alignment of lower incisors without the use of retainers. Eur. J. Orthod., 27(3):209-14, 2005.

Arnone, R. Bonding orthodontic lower 3 to 3 retainers with a rubber dam: a second generation step-bystep procedure. Am. J. Orthod. Dentofacial Orthop., 116(4):432-4, 1999.

Artun, J.; Spadafora, A. T. \& Shapiro, P. A. A 3-year follow-up study of various types of orthodontic canine-to-canine retainers. Eur. J. Orthod., 19(5):501-9, 1997.

Baysal, A. \& Uysal, T. Resin-modified glass ionomer cements for bonding orthodontic retainers. Eur. J. Orthod., 32(3):254-8, 2010.

Butler, J. \& Dowling, P. Orthodontic bonded retainers. J. Ir. Dent. Assoc., 51(1):29-32, 2005. 
Cooke, M. E. \& Sherriff, M. Debonding force and deformation of two multi-stranded lingual retainer wires bonded to incisor enamel: an in vitro study. Eur. J. Orthod., 32(6):741-6, 2010.

Gardner, G. D.; Dunn, W. J. \& Taloumis, L. Wear comparison of thermoplastic materials used for orthodontic retainers. Am. J. Orthod. Dentofacial Orthop., 124(3):294-7, 2003.

Lee, K. D. \& Mills, C. M. Bond failure rates for V-loop vs straight wire lingual retainers. Am. J. Orthod. Dentofacial Orthop., 135(4):502-6, 2009.

Niegel, S. Prefabricated retainers for orthodontic appliances. Dtsch. Zahnarztl. Z., 29(4):424-9, 1974.

Norton, R. Y. Rapid fabrication of orthodontic retainers. Aust. J. Dent., 55(2):135-8, 1951.

Reynolds, I. R. \& von Fraunhofer, J. A. Direct bonding of orthodontic brackets--a comparative study of adhesives. Br. J. Orthod., 3(3):143-6, 1976.

Santos, B. M.; Pithon, M. M.; Ruellas, A. C. \& Sant'Anna, E. F. Shear bond strength of brackets bonded with hydrophilic and hydrophobic bond systems under contamination. Angle Orthod., 80(5):963-7, 2010.

Ulker, M.; Uysal, T.; Ramoglu, S. I. \& Ucar, F. I. Bond strengths of an antibacterial monomer-containing adhesive system applied with and without acid etching for lingual retainer bonding. Eur. J. Orthod., 31(6):658-63, 2009.

Usümez, S.; Buyukyilmaz, T. \& Karaman, A. I. Effects of fast halogen and plasma arc curing lights on the surface hardness of orthodontic adhesives for lingual retainers. Am. J. Orthod. Dentofacial Orthop., 123(6):641-8, 2003.

White, L. W. An expedited indirect bonding technique. J. Clin. Orthod., 35(1):36-41, 2001.
Correspondence to:

Matheus Melo Pithon

Av. Otávio Santos, 395, sala 705

Centro Odontomédico Dr. Altamirando da Costa Lima,

Bairro Recreio

CEP 45020-750

Vitória da Conquista

Bahia

BRAZIL

Email: matheuspithon@gmail.com

Received: 12-02-2013

Accepted: 09-10-2013 